\title{
Foraging behaviour of South American fur seals Arctocephalus australis: extracting fine scale foraging behaviour from satellite tracks
}

\author{
David Thompson*, Simon E. W. Moss, Phil Lovell \\ Natural Environment Research Council (NERC), Sea Mammal Research Unit, Gatty Marine Laboratory, \\ University of St Andrews, St Andrews KY16 8JH, UK
}

\begin{abstract}
Industrial exploitation of marine resources may adversely affect marine top predators, but protecting important foraging areas may reduce impacts. Such areas may be relatively small and discrete, and anthropogenic disturbance effects may also be geographically or temporally localised. Avoiding overlap may be simple and inexpensive, but requires accurate, fine-resolution data on habitat use. Here we report the results of a satellite telemetry-based study of foraging behaviour of South American fur seals in relation to proposed offshore oil exploration areas in Falkland waters. We developed a simple track-smoothing algorithm incorporating estimated location error and temporal distribution of position fixes and used the temporal frequency distribution of received transmissions to infer haulout events and further constrain the tracking data. The accuracy of smoothed data was tested against independently derived foraging-trip data and then used to describe foraging behaviour of 14 fur seals between October 1999 and September 2000 and demonstrate a dramatic seasonal pattern in foraging locations. Early in lactation, all seals made short-duration, nocturnal foraging trips, and foraging was restricted to a small area within $20 \mathrm{~km}$ of the breeding site. By late summer, trips were over $6 \mathrm{~d}$ long and ranged over $195 \mathrm{~km}$ from the island. Overall, 15 to $20 \%$ of late lactationphase foraging occurred in the oil exploration zone. Restricted foraging ranges early in lactation reduced the likelihood of interactions with offshore activities. Counterintuitively offshore activities may be less disturbing when pups are young.
\end{abstract}

KEY WORDS: ARGOS $\cdot$ Satellite telemetry $\cdot$ Filter $\cdot$ Fur seal $\cdot$ Foraging $\cdot$ Tracks

Resale or republication not permitted without written consent of the publisher

\section{INTRODUCTION}

As exploitation of marine resources and associated marine industrial activities increase (GESAMP 1998, Agardy 2000, Northridge 2001), populations of marine predators, which evolved under particular regimes of natural environmental conditions, are being exposed to new pressures. For example, the rapid development of intensive fisheries or intense industrial disturbances may alter foraging habitats to such an extent that populations can no longer meet their foraging requirements. If these changes exceed a population's ability to accommodate, the results may be catastrophic.
One method for minimising harmful interactions is to identify and protect critically important foraging habitats. In the absence of behavioural information, large areas of ocean must be regarded as potentially important for each population. However, the areas of importance to individuals or even populations of marine mammals and birds may be relatively small and discrete (McConnell et al. 1999). Disturbances due to offshore activities may also be geographically and temporally localised. Therefore, avoiding overlap may be simple and relatively inexpensive. Investing in studies to identify the foraging areas of marine mammals and birds may be beneficial from both conservation and economic viewpoints. 
In order to best manage such interactions, we must have appropriate behavioural data for each species, at sufficient spatial and temporal resolution to be able to identify and delimit areas and times of potential conflict. Recently, satellite tracking, using the ARGOS/ CLS system, has become a widely used method for studying the movement patterns of marine mammals and birds (e.g. Jouventin \& Weimerskirch 1990, McConnell et al. 1992a, 1999, Merrick et al. 1994, Georges et al. 2000a, Campagna et al. 2001). However, location estimates derived from such satellite telemetry are of variable quality and may contain sufficient error to effectively mask small-scale and/or shortduration movements (Argos 1989). For studies of wideranging marine predators, the scale of movements may be large relative to these errors (Jouventin \& Weimerskirch 1990, McConnell et al. 1992b, McConnell \& Fedak 1996). In such cases, filters based on maximum feasible travel speed have been used to remove points with unacceptably high errors (McConnell et al. 1992a, Austin et al. 2003). The remaining points may then provide an acceptable approximation to the animal's track (McConnell et al. 1992b, McConnell \& Fedak 1996, Hull et al. 1997, Catard et al. 2000). To minimise the effects of the residual errors, estimates of movement parameters such as travel speed have usually been based on daily mean locations or on comparison of widely separated points (Hays et al. 2001). However, this method does not reduce the noise in the remaining points, and in the case of local foragers such as fur seals the remaining error may still be sufficient to mask short-range and short-duration trips. In order to adequately describe fine-scale foraging behaviour, we must therefore improve the accuracy of the satellite telemetry tracks.

Here we describe the results of a satellite telemetry-based study of the movements and foraging behaviour of South American fur seals Arctocephalus australis in the Falkland Islands. We develop a smoothing algorithm for satellite telemetry tracks that utilises all the location data and incorporates information on the error distributions and the temporal spread of the location data. The resolution of tracks is further enhanced by incorporating inferred behaviour derived from the temporal patterns of transmissions received by the satellite from the seals. The algorithm was tested with independently derived foraging-trip data, and then the smoothed tracks were used to describe fur seal movements in relation to planned oil-field developments.

\section{MATERIALS AND METHODS}

We used location data from the ARGOS/CLS satellite tracking system to describe foraging behaviour of fur seals at each of 3 stages of the breeding cycle: early (January to March) — when the pups were small; mid (May to September) - during the post-moult period; late (October to December) pre-breeding, when pups were large and females were heavily pregnant.

Capture and tagging. Field studies were conducted at a breeding colony on Bird Island ( $52^{\circ} 17^{\prime} \mathrm{S}, 60^{\circ} 92^{\prime} \mathrm{W}$ ) in the southwest of the Falkland Islands (see Fig. 4). We caught 13 adult female and 1 sub-adult male fur seals between October 1999 and April 2000. Seals were caught on land using hand nets, sedated with intra-muscular doses of 0.08 to $0.1 \mathrm{mg} \mathrm{kg}^{-1}$ of Zoletil (Baker et al. 1990) and fitted with satellite transmitters (ST10 transmitters; dimensions $11.7 \times 4.7 \times 2.2 \mathrm{~cm}$; Telonics) (Table 1). Of the 14 fur seals, 10 were also fitted with data loggers to record time, depth and swimming speed (MK6 time-depth recorders, TDRs; dimensions $7.5 \times 5.5 \times 3 \mathrm{~cm}_{\text {; }}$ Wildlife Computers) (Table 1). Devices were glued to the guard hairs in the mid-dorsal region using fast-setting epoxy resin (Fedak et al. 1983). Satellite transmitters were programmed to transmit at $45 \mathrm{~s}$ intervals when at the surface, and to switch off when dry for more than $10 \mathrm{~min}$. TDRs were programmed to sample depth and speed at $5 \mathrm{~s}$ intervals.

Location-data smoothing algorithm. Position fixes provided by the ARGOS/CLS tracking system are each assigned a location-quality (LQ) index based on the characteristics of the received signals (Argos 1989). These range from highest quality (LQ3) with an
Table 1. Arctocephalus australis. Summary of seal capture, transmitter attachments, anaesthesia (intramuscular) and tracking periods. TDR: time-depth recorder; No. of days: number of days that seals were tracked. Adult females, except: ${ }^{a}$ sub-adult male. The last 4 individuals were not fitted with TDR

\begin{tabular}{|lccccr|}
\hline $\begin{array}{l}\text { Satellite } \\
\text { transmitter }\end{array}$ & $\begin{array}{c}\text { Tagging date } \\
(\mathrm{dd} / \mathrm{mm} / \mathrm{yy})\end{array}$ & $\begin{array}{c}\text { Mass } \\
(\mathrm{kg})\end{array}$ & $\begin{array}{c}\text { TDR data } \\
\text { recovered }\end{array}$ & $\begin{array}{c}\text { Drug dose } \\
(\mathrm{ml})\end{array}$ & $\begin{array}{r}\text { No. of } \\
\text { days }\end{array}$ \\
\hline $28481-99$ & $22 / 10 / 99$ & 50 & No & 0.5 & 42.4 \\
$28482-99$ & $23 / 10 / 99$ & 50 & No & 0.5 & 79.2 \\
$28483-00$ & $26 / 1 / 00$ & 60 & No & 0.65 & 31.4 \\
$28484-00$ & $26 / 1 / 00$ & 40 & Yes & 0.6 & $10 / 1$ \\
$28485-00$ & $27 / 1 / 00$ & 50 & No & 0.6 & 56.3 \\
$28486-00$ & $28 / 1 / 00$ & 45 & No & 0.5 & 36.6 \\
$28487-00$ & $28 / 1 / 00$ & 55 & No & 0.5 & $55 / 1$ \\
$28488-00$ & $29 / 1 / 00$ & 55 & No & 0.55 & 59.8 \\
$28489-00$ & $30 / 1 / 00$ & 50 & Yes & 0.5 & 9.6 \\
$28490-00$ & $30 / 1 / 00$ & 50 & No & 0.5 & 44.5 \\
$28491-00^{a}$ & $31 / 1 / 00$ & 45 & - & 0.3 & 14.3 \\
$28492-00$ & $31 / 1 / 00$ & 60 & - & 0.5 & 49.5 \\
$28493-00$ & $30 / 4 / 00$ & 65 & - & 0.6 & 40.2 \\
$28494-00$ & $30 / 4 / 00$ & 47.5 & - & 0.45 & 163.5 \\
& & & & & \\
\hline
\end{tabular}


estimated standard deviation of $150 \mathrm{~m}$ to the lowest quality (LQ-2) which have an unclassified error. Several authors have described error distributions for reallocation data (Keating 1994, 1995, Britten et al. 1999, Walton et al. 2001, Vincent et al. 2002). Here we used error data from a study of the accuracy of location data derived from satellite transmitters on freely diving captive grey seals (Vincent et al. 2002). Data from captive seals indicated that the error distributions for latitude and longitude were different (Vincent et al. 2002), so latitude and longitude data series were smoothed separately.

Each location fix was first assigned a weighting equal to the inverse of the estimated variance for its particular LQ (values of LQ variances used are given in Table 2). Then, for each individual location fix, we applied a time-weighted normal-density kernel smoother to the location-quality-weighted points in the dataset; i.e. the time-weighting for each point was set to equal the probability density for the elapsed time between the occurrence of the current point $\left(t_{\mathrm{i}}\right)$ and the point of interest $\left(t_{\mathrm{j}}\right)$ read from a normal distribution with a mean of zero and a standard deviation $(\sigma)$. Appropriate $\sigma$ values were selected from the results of a simulation. Thus smoothed latitude and longitude values were calculated as:

$$
\hat{Y}_{j}=\frac{1}{\sum_{i} q_{i} \times k\left(t_{j}-t_{i}, 0, \sigma\right)} \sum_{i} q_{i} \times k\left(t_{j}-t_{i}, 0, \sigma\right) \times y_{i}
$$

where: $\hat{Y}_{j}=$ smoothed value of the $j$ th latitude or longitude, $q_{i}=$ inverse of the variance estimate for the LQ of the $i$ th position, $k\left(t_{j}-t_{i,}, \sigma\right)=$ the probability density of the value $t_{j}-t_{i}$ from a normal distribution with mean $=0$ and standard deviation $=\sigma, t_{i}=$ time of $j$ th location fix, and $t_{i}=$ time of $i$ th location fix.

The $\sigma$ value used for the time-weighting was arrived at by simulation. Straight-line, sinusoidal and circular swimming paths were simulated. Preliminary examination of the tracking data indicated that the fur seals travelled at around $1 \mathrm{~m} \mathrm{~s}^{-1}$, so simulated tracks were generated assuming a constant travelling speed of $1 \mathrm{~m}$ $\mathrm{s}^{-1}$. Early in the breeding cycle, fur seals appeared to be performing daily foraging trips, so sinusoidal paths were assigned a wavelength of $80 \mathrm{~km}$ to produce 1 complete oscillation $\mathrm{d}^{-1}$ and circular paths were assigned a radius of $13 \mathrm{~km}$ producing 1 revolution $\mathrm{d}^{-1}$.

Location fixes were positioned along the paths at time intervals similar to those observed in a sample of the fur seal track-data. Points were assigned LQs in the same sequence as those observed in the fur seal sample. Error, equal to a randomly selected value from a normal distribution with a mean of zero and the estimated variance for the appropriate LQ (Table 2), was added to each point.
The smoothing algorithm was applied to each path with a range of values for $\sigma$. Residual error was calculated for each simulation as the sum of the radial displacements of the smoothed points from original errorfree points. The residual error was then plotted against $\sigma$ for each simulated track. The minimum was estimated by eye and this value was chosen as the appropriate value of $\sigma$ for the smoothing algorithm.

Incorporating inferred behaviour. To save battery life, the satellite transmitters were configured to switch off shortly after haulout. Satellite coverage is not continuous, therefore transmitters often went into haulout resting mode without any on-land locations being received. Transmissions did not resume until the transmitters had been submerged at least once, so the first position fixes after a haulout event were usually out at sea. It was therefore often not possible to determine exactly when or even if a seal returned to the breeding site at a particular time.

However, the temporal distribution of received transmissions (uplinks) contains information that may allow us to determine when a seal was swimming or hauled out and therefore improve estimates of haulout times. To examine this, we plotted the frequency distribution of uplinks from 4 of the seals when they were known to be at sea, for a total of $153 \mathrm{~d}$; during this time 9100 signals were detected. The temporal pattern is typical of the uplink distribution for the ARGOS system. Few uplinks were received between 16:00 and 20:00 h local time. Outside this $4 \mathrm{~h}$ period, uplinks were received at a mean rate of $2.96 \mathrm{~h}^{-1}$ (Fig. 1), although temporal distribution was not strictly uniform, e.g. there were fewer uplinks than would be expected during the late evening. For simplicity, we assumed that there was an underlying uniform distribution, with an uplink rate equal to half the mean rate (1.5 uplinks $\mathrm{h}^{-1}$ ) and used this assumption to conservatively estimate the probability of receiving no signals in any time period.

If we assume a Poisson process, with an arrival rate of $1.5 \mathrm{~h}^{-1}$, the probability of receiving no uplinks in $2 \mathrm{~h}$ would be 0.05 and in $3 \mathrm{~h}$ would be 0.01 . Thus, for any time outside the period 16:00 to 20:00 h, if no signal

Table 2. Arctocephalus australis. Estimated standard deviation $(\mathrm{km})$ of position fixes of different location qualities (LQ) defined by ARGOS/CLS tracking system (Vincent et al. 2002)

\begin{tabular}{|rcc|}
\hline LQ & Latitude & Longitude \\
\hline 3 & 0.157 & 0.295 \\
2 & 0.259 & 0.485 \\
1 & 0.494 & 1.021 \\
0 & 2.271 & 3.308 \\
-1 & 0.762 & 1.244 \\
-2 & 4.596 & 7.214 \\
\hline
\end{tabular}




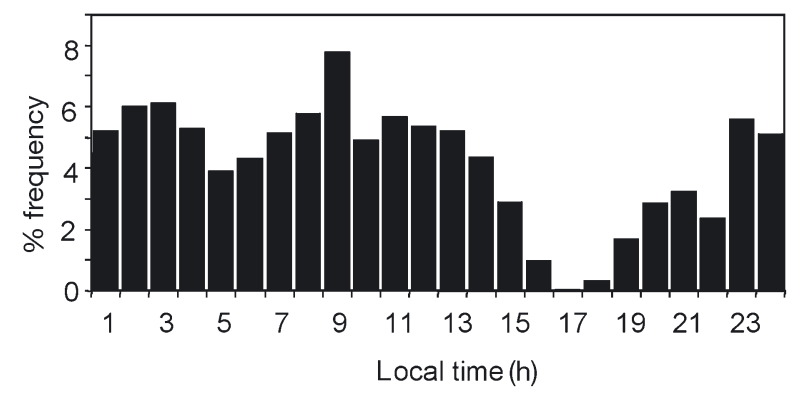

Fig. 1. Arctocephalus australis. Frequency distribution (\%) of number of uplinks $\mathrm{h}^{-1}$ received from satellite transmitters on South American fur seals, swimming at sea. Reduced frequency of uplinks received during a $4 \mathrm{~h}$ period between 16:00 and 20:00 $\mathrm{h}$ resulted from uneven temporal distribution of overflights by the 2 polar orbiting satellites

was received for a period of $3 \mathrm{~h}$ we assumed the seal was hauled out $1.5 \mathrm{~h}$ after the last transmission and reentered the water $1.5 \mathrm{~h}$ before the first transmission. A preliminary examination of the unfiltered data indicated that the study seals rarely if ever, hauled out at sites other than the breeding island. Therefore, when uplink patterns suggested a haulout event, we inserted a high-quality location fix representing the breeding colony on Bird Island. Each insertion was examined and only 2 misallocations were found, 1 where the seal had switched to haulout at Beaver Island, $50 \mathrm{~km}$ away, and 1 where a seal was over $50 \mathrm{~km}$ from land.

Verification of smoothing algorithm. Dive-behaviour data from 2 fur seals were used to verify the start and end times of trips estimated from the smoothed location data. All dive records were plotted (EXCEL Microsoft), and trip start and end times, and dive-bout start and end times were estimated by eye.

Movements and foraging trip characteristics. The modified location data sets, incorporating inferred haulout events, were passed to the time- and locationweighted smoothing algorithm described above. Swimming tracks were plotted as maps and as distance from the breeding site. Trip and visit durations were estimated by eye. For each position fix we calculated the travelling speeds from the previous and to the next location in the smoothed track-data. Speeds were classed as slow $\left(<0.5 \mathrm{~m} \mathrm{~s}^{-1}\right)$ and fast $\left(>0.5 \mathrm{~m} \mathrm{~s}^{-1}\right)$.

\section{RESULTS}

\section{Smoothing simulations}

Applying the smoothing algorithm to the simulated data had a dramatic effect on the accuracy of the track. There was a clear improvement in the fit to the original track in all simulations with values of $\sigma$ greater than a few minutes. Fig. 2 shows the simulated track, the data with error added and the best-fit smoothed data for each of the 3 types of simulated path. The minimum residual error occurred at different values of $\sigma$ for each path type, but the minimum was not sharp for any of the simulated tracks and a value of $2.5 \mathrm{~h}$ was chosen as the best fit overall. In the example shown, the smoothed data do not apparently fit well to the sinusoidal track. This is a consequence of undersampling rather than inappropriate smoothing.

Fig. 3 shows the effect of the smoothing process on a sample of the tracking data for a period of local foraging by a female fur seal early in the breeding cycle. The raw data contained enough noise to completely mask her behaviour, there were no definable haulout periods, and it was not clear if there were any discrete trips. Adding in the assumed haulout times and running the smoothing algorithm resolved the data into a series of short-duration nightly trips out to sea.

\section{Validation of smoothing algorithm}

TDRs were recovered from 2 seals in February 2000, after periods of 7 and $9 \mathrm{~d}$ of tracking, respectively. However, recapture operations caused widespread disturbance of the colony and further attempts were abandoned.

Complete records of dive depth and swimming speed were obtained for 14 short foraging trips. All 14 trips evident in the TDR data were clearly identifiable in the smoothed track-data and there were no erroneous trips. Times of departure and return to the island were estimated by eye independently from the smoothed track data and the TDR data (Table 3). In each case, the start and end times of the trips defined by TDR records agreed closely with the estimated start and end times from the satellite location data. Start times from the track data were, on average, $0.2 \mathrm{~h}$ earlier than estimates from TDR records $(\max =2.7 \mathrm{~h}$, $\mathrm{SD}=1.34, \mathrm{n}=14)$, and end times were $0.8 \mathrm{~h}$ later $(\max$ $=3.4 \mathrm{~h}, \mathrm{SD}=1.53, \mathrm{n}=14)$. Estimated trip durations from the track data were therefore slightly longer than from the TDR data, but the difference was not significant (track data mean $=7 \mathrm{~h} 28 \mathrm{~min}$, TDR data mean $=6$ h $37 \mathrm{~min}$; Student's paired-sample $t=0.85$, $\mathrm{df}=13, \mathrm{p}<0.2$ ).

Trips usually comprised an initial period of active swimming, close to the surface, followed by a period of intense diving, and ended with another period of active swimming close to the surface. Surface swimming is assumed to represent transit to and from the foraging sites. The duration of outbound transit swimming varied from 0 to $147 \mathrm{~min}$ (mean = $41 \mathrm{~min}$ ). In 

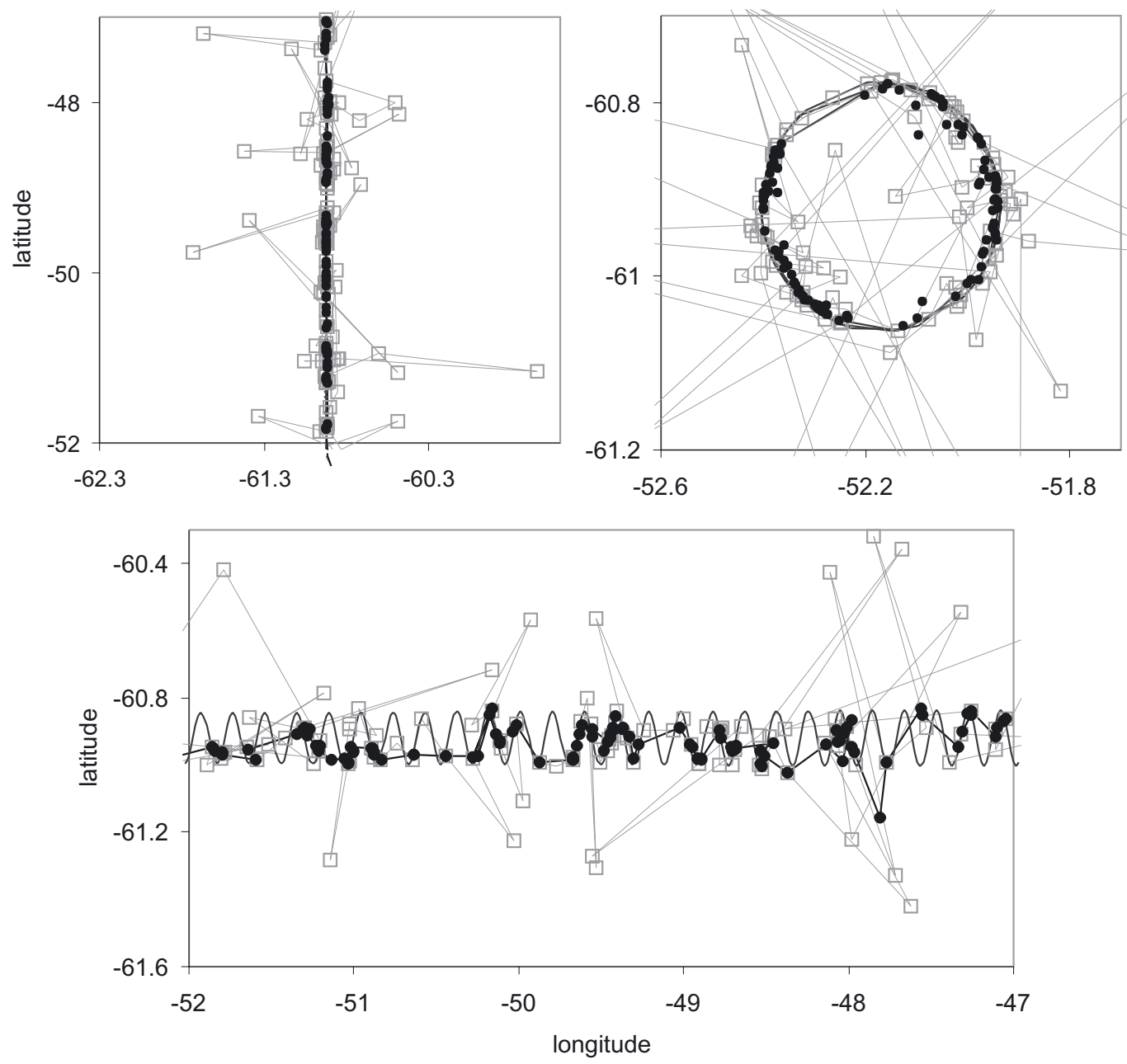

Fig. 2. Arctocephalus australis. Simulated swimming tracks with positions of simulated locations with error added ( $\square$ ) and smoothed location points (๑). Simulation methods are described in 'Materials and methods'

5 trips there was little or no outbound transit swim, i.e. diving activity started within a few minutes of entering the water and therefore started close to the breeding colony. Return-transit swimming lasted from 11 to $242 \mathrm{~min}$ (mean = $87 \mathrm{~min}$ ). Mean swimming speed during these periods was around $1.5 \mathrm{~m} \mathrm{~s}^{-1}$. If we assume that seals swam directly from foraging sites to the haulout, then the estimated foraging sites used by these 2 seals in February would have been between 1.5 and $21 \mathrm{~km}$ from the breeding beach, similar to the apparent distances from the smoothed track-data.

\section{Movements}

Swimming tracks were obtained from 14 satellite transmitter-equipped fur seals at

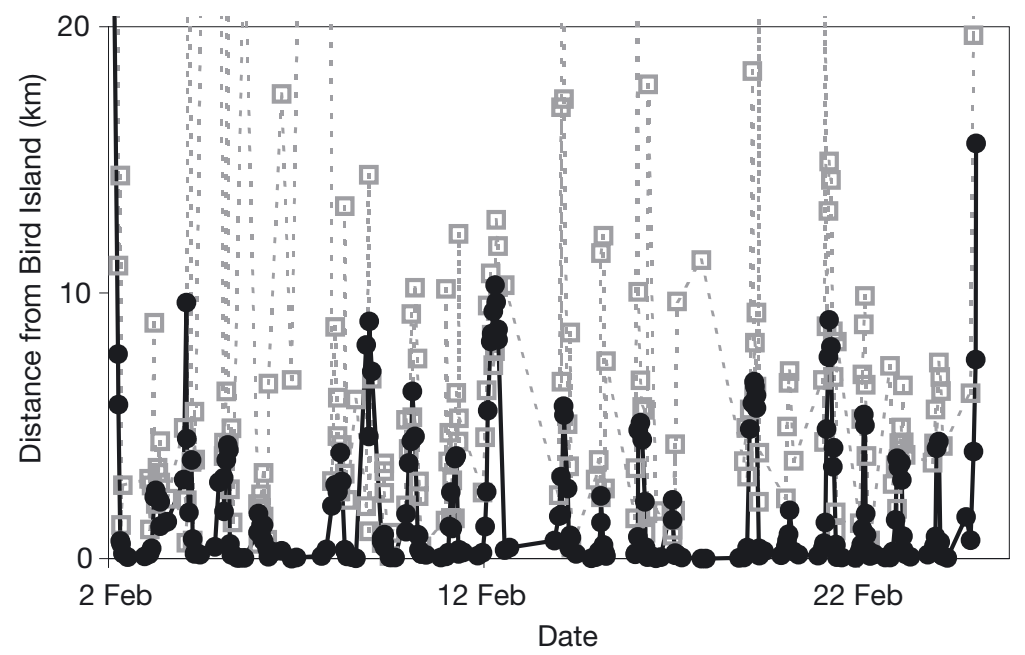

Fig. 3. Arctocephalus australis. Effect of smoothing process on sample of fur seal tracking-data, expressed as distance from breeding site against time. $(\square)$ unfiltered, raw data; $(\bullet)$ smoothed locations. Several clearly defined, short-duration trips apparent in smoothed data are not apparent in raw data 
Table 3. Arctocephalus australis. Comparison of timings, durations and distances of foraging trips by 2 South American fur seals derived from smoothed swimming-track data and independent dive-behaviour data; TDR: time-depth recorder, 'Start' and 'End' time-columns show local time of day

\begin{tabular}{|c|c|c|c|c|c|c|c|c|c|c|}
\hline \multirow{3}{*}{ Date } & \multicolumn{6}{|c|}{ TDR data } & \multicolumn{4}{|c|}{ Smoothed track data } \\
\hline & \multirow[b]{2}{*}{ Start } & \multicolumn{3}{|c|}{ Time } & \multicolumn{2}{|c|}{ Swimming } & \multirow[b]{2}{*}{ Start } & \multicolumn{2}{|c|}{-Time } & \multirow{2}{*}{$\begin{array}{c}\text { Swimming } \\
\text { distance } \\
(\mathrm{km})\end{array}$} \\
\hline & & End & $\begin{array}{c}\text { Duration } \\
\text { (h:min) }\end{array}$ & $\begin{array}{c}\text { Transit } \\
\text { (min) }\end{array}$ & $\begin{array}{l}\text { Speed } \\
\left(\mathrm{m} \mathrm{s}^{-1}\right)\end{array}$ & $\begin{array}{l}\text { Distance } \\
\quad(\mathrm{km})\end{array}$ & & End & $\begin{array}{c}\text { Duration } \\
\text { (h:min) }\end{array}$ & \\
\hline \multicolumn{11}{|l|}{ Seal 4} \\
\hline $27 \mathrm{Jan}$ & $19: 25$ & $04: 15$ & $8: 50$ & 111 & 1.44 & 9.6 & 19:00 & 06:00 & $11: 00$ & 23 \\
\hline $29 \mathrm{Jan}$ & $21: 50$ & $04: 30$ & $7: 02$ & 282 & 1.07 & 18.1 & $20: 00$ & 04:00 & $8: 00$ & 13.3 \\
\hline $30 \mathrm{Jan}$ & $21: 23$ & $04: 25$ & $6: 40$ & 66 & 1.50 & 5.9 & $21: 00$ & 03:00 & $6: 00$ & 6.6 \\
\hline $31 \mathrm{Jan}$ & $21: 45$ & 09:15 & $11: 30$ & 70 & 1.53 & 6.4 & $22: 00$ & $10: 00$ & $12: 00$ & 17 \\
\hline $1 \mathrm{Feb}$ & $0: 55$ & $04: 30$ & $3: 35$ & 11 & 1.01 & 0.7 & 01:00 & 05:30 & $4: 30$ & 4 \\
\hline 2 Feb & $21: 42$ & $05: 45$ & $8: 03$ & 39 & 1.40 & 3.3 & $19: 00$ & 05:00 & $10: 00$ & 6.6 \\
\hline 3 Feb & $21: 57$ & 05:05 & $7: 08$ & 40 & 1.48 & 3.6 & $23: 00$ & $08: 30$ & $9: 30$ & 4.6 \\
\hline \multicolumn{11}{|l|}{ Seal 9} \\
\hline 31 Jan & $21: 25$ & $04: 20$ & $6: 55$ & 77 & 1.47 & 6.8 & $20: 00$ & 05:00 & 9:00 & 3 \\
\hline $1 \mathrm{Feb}$ & $21: 55$ & $03: 45$ & $5: 50$ & 90 & 1.14 & 6.2 & $20: 00$ & 06:00 & $10: 00$ & 5.3 \\
\hline 2 Feb & $21: 45$ & 03:20 & $5: 35$ & 55 & 1.43 & 4.7 & $23: 00$ & 01:30 & $2: 30$ & 3.5 \\
\hline 3 Feb & $21: 57$ & 02:00 & $4: 03$ & 27 & 1.06 & 1.7 & $23: 00$ & 01:00 & $2: 00$ & 1 \\
\hline 4 Feb & $21: 50$ & $03: 26$ & $5: 36$ & 53 & 1.34 & 4.3 & $23: 00$ & 05:00 & $6: 00$ & 3.3 \\
\hline 5 Feb & $21: 35$ & $04: 10$ & $6: 35$ & 83 & 1.41 & 7.0 & 0.875 & 06:00 & 9:00 & 5.5 \\
\hline 6 Feb & $21: 30$ & $02: 45$ & $5: 15$ & 75 & 1.28 & 5.8 & $23: 00$ & 04:00 & $5: 00$ & 4.5 \\
\hline
\end{tabular}

Bird Island. Excluding 2 transmitters that were removed after 9 and $10 \mathrm{~d}$, the mean tracking period was $56 \mathrm{~d}$ (range 15 to 164). The entire swimming tracks of 264 foraging trips were recorded during $693 \mathrm{~d}$ of seal activity.

The smoothed swimming-tracks of all 14 deployments are shown in Fig. 4. The maximum distance from Bird Island was $195 \mathrm{~km}$, during the last prebreeding trip by FS2 in December 1999. Seals foraged over a wide area, with a wide range of water depths, from 20 to $30 \mathrm{~m}$ close to Bird Island, out to water 500 to $600 \mathrm{~m}$ deep.

\section{Seasonal patterns}

There was a strong seasonal pattern in the distribution of foraging effort by the 2 seals at Bird Island. During the spring (October to December 1999), seals performed long-range, long-duration foraging trips to the south of Bird Island (Fig. 5a, Table 4). Both seals foraged in an area southwest of the islands. Approximately $30 \%$ of the total time at sea was spent within an area scheduled for oil exploration.

All 10 seals tracked throughout late January and February (i.e. the early part of the 2000 breeding season) concentrated their activity within $20 \mathrm{~km}$ of Bird Island and performed sequences of short, local trips (Fig. 5b; Table 4). Mean trip duration in January and February was more than 1 order of magnitude shorter than the mean duration for October to December; 5 of the females were tracked through to late March. Trip duration and trip distance were significantly greater in March than in February (Table 4; duration: $t=6.2$, $\mathrm{p}<0.001$; distance: $t=5.6, \mathrm{p}<0.001)$. All 5 seals expanded their foraging ranges, but the majority of the location fixes were inshore close to fur seal breeding-sites on Beaver and New Islands to the northwest of Bird Island (Fig. 5c). Of the 5 seals tracked in March, 3 made long trips to the south of

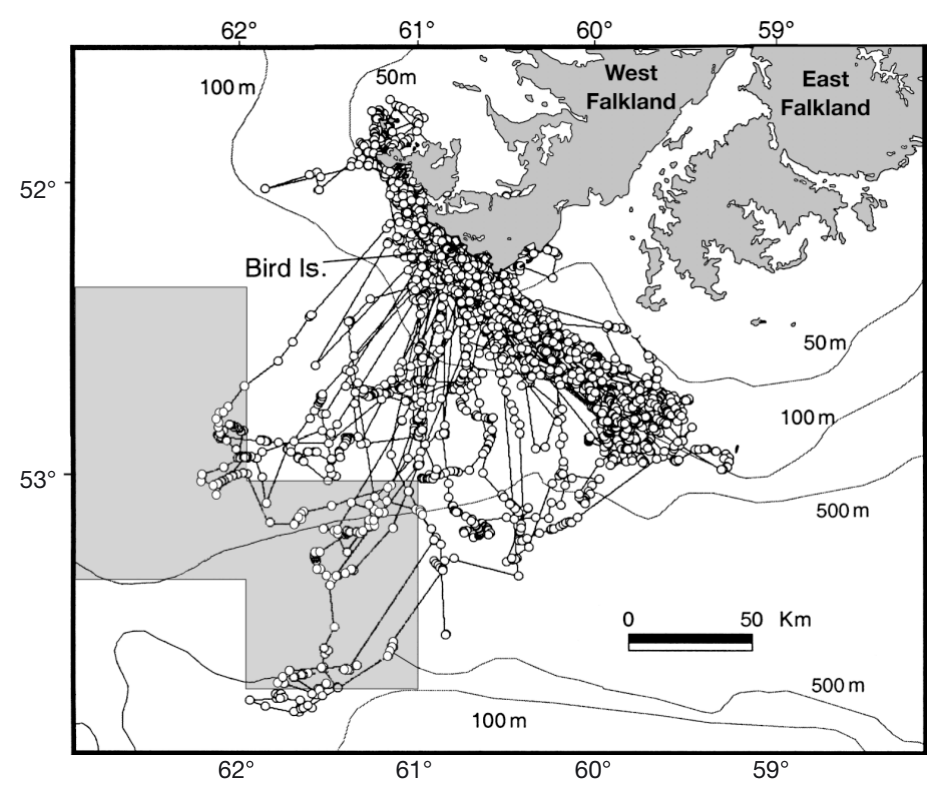

Fig. 4. Arctocephalus australis. Smoothed swimming tracks of 13 adult females and 1 sub-adult male, between 28 October 1999 and 20 September 2000. Light-grey shaded area represents area of oil exploration licences 
(a)

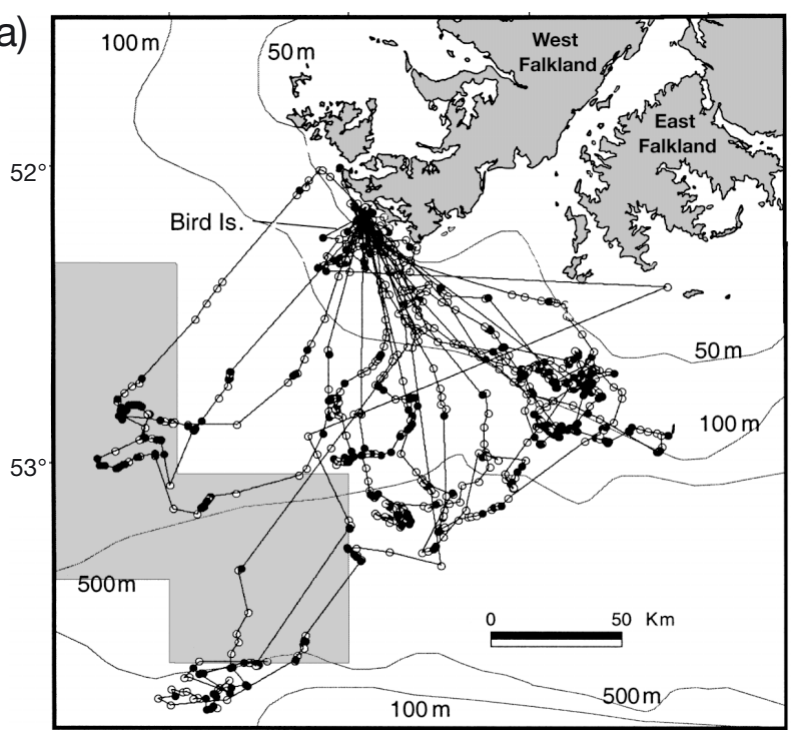

(b)

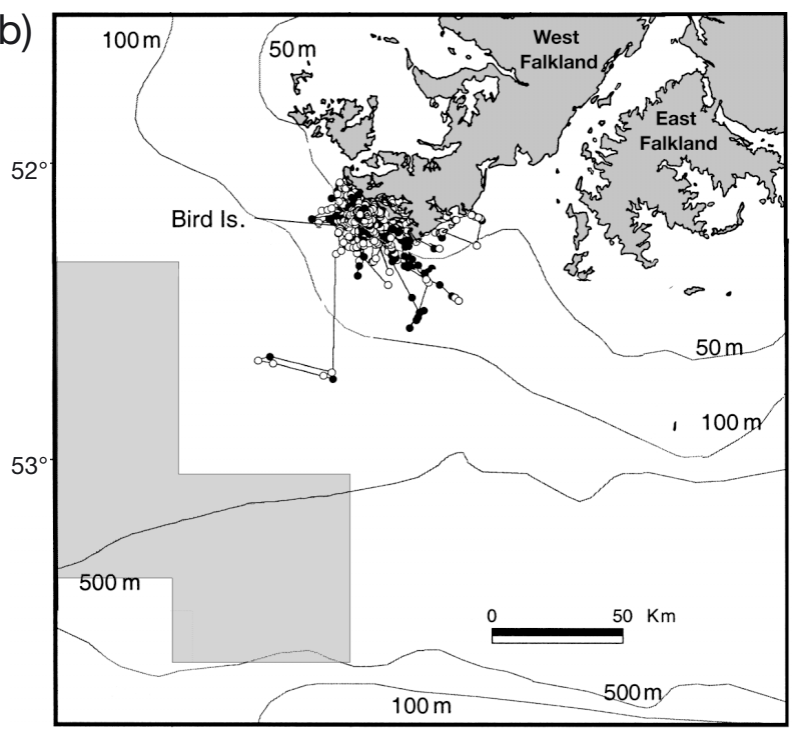

(c)



(d)

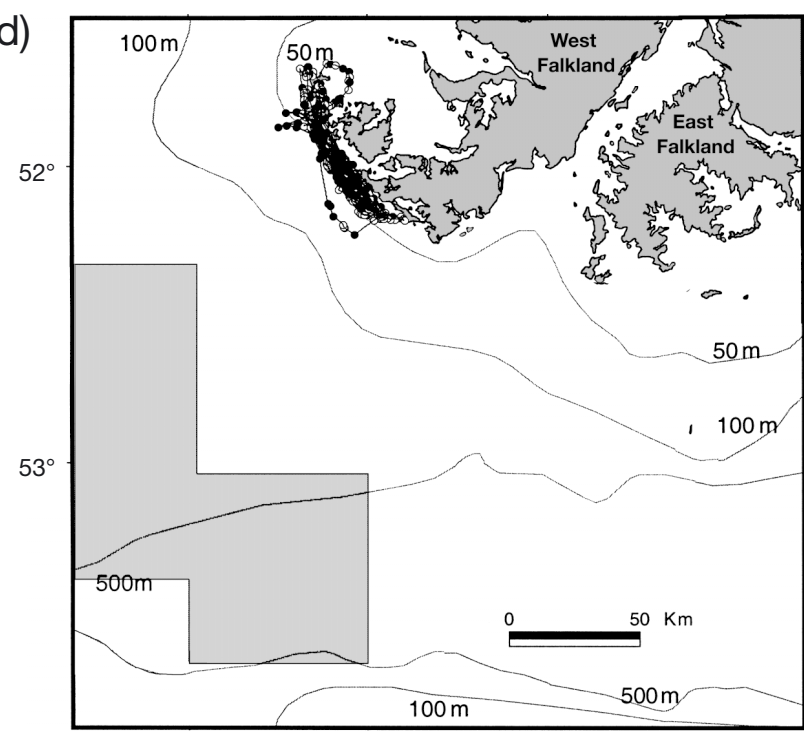

(e)

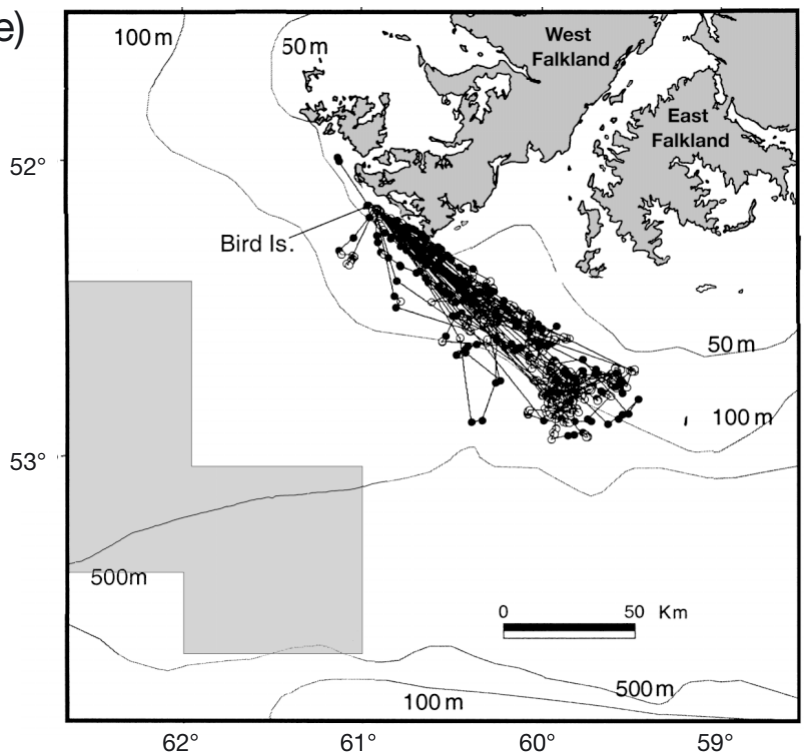

Fig. 5. Arctocephalus australis. Swimming tracks of adult females tagged at Bird Island, Falkland Islands. Locations coded by travel speed: $(\bullet)<0.5 \mathrm{~m} \mathrm{~s}^{-1},(0)>0.5 \mathrm{~m} \mathrm{~s}^{-1}$. Lightgrey shaded area represents area of oil exploration licences. (a) Tracks of 2 adult females between 28 October 1999 and 10 January 2000. (b) Tracks of 9 adult females and 1 sub-adult male between 28 January and 26 February 2000; dense clump of points around Bird Island contains 2210 separate satellite location fixes at sea. (c) Tracks of the 5 females that continued to transmit between 27 February 2000 and moult in late March; all 5 seals increased their foraging range, 3 made offshore trips to oil exploration zone. (d) Tracks of 2 adult females between 30 April and 31 May 2000. (e) Tracks of the 2 females in (d) but tracked between 30 May and 14 September 2000; the seals switched foraging sites on the same date 
Table 4. Arctocephalus australis. Summary statistics of trip duration, trip distance and breeding colony attendance during different months

\begin{tabular}{|c|c|c|c|c|c|c|c|c|c|c|}
\hline \multirow{2}{*}{ Period } & \multirow{2}{*}{$\begin{array}{l}\text { No. of } \\
\text { seals }\end{array}$} & \multicolumn{3}{|c|}{ Trip duration (h) } & \multicolumn{3}{|c|}{ Visit duration (h) } & \multicolumn{3}{|c|}{ Max. distance (km) } \\
\hline & & Mean & $\mathrm{SD}$ & $\mathrm{n}$ & Mean & $\mathrm{SD}$ & $\mathrm{n}$ & Mean & $\mathrm{SD}$ & $\mathrm{n}$ \\
\hline October-December & 2 & 126 & 22.9 & 10 & 104 & 28.7 & 9 & 127 & 27.3 & 10 \\
\hline January & 1 & 11.4 & 7.2 & 7 & 35.4 & 28.6 & 7 & 19 & 10.7 & 7 \\
\hline February & 10 & 11.8 & 12.9 & 158 & 24.6 & 15.5 & 158 & 7.9 & 12.9 & 158 \\
\hline March & 5 & 30.7 & 36.1 & 41 & 26.7 & 20.7 & 41 & 30.6 & 39.1 & 41 \\
\hline May & 2 & 53.9 & 32.4 & 16 & 32.5 & 16.6 & 16 & 42.5 & 16.6 & 16 \\
\hline June-September & 2 & 100.6 & 48.3 & 16 & 45.1 & 14.0 & 15 & 92.7 & 20.1 & 16 \\
\hline
\end{tabular}

Bird Island and spent a total of $200 \mathrm{~h}$ inside the oil exploration zone. This represented $17 \%$ of the total time recorded at sea during March. All 5 seals stopped transmitting in late March, commensurate with the annual moult.

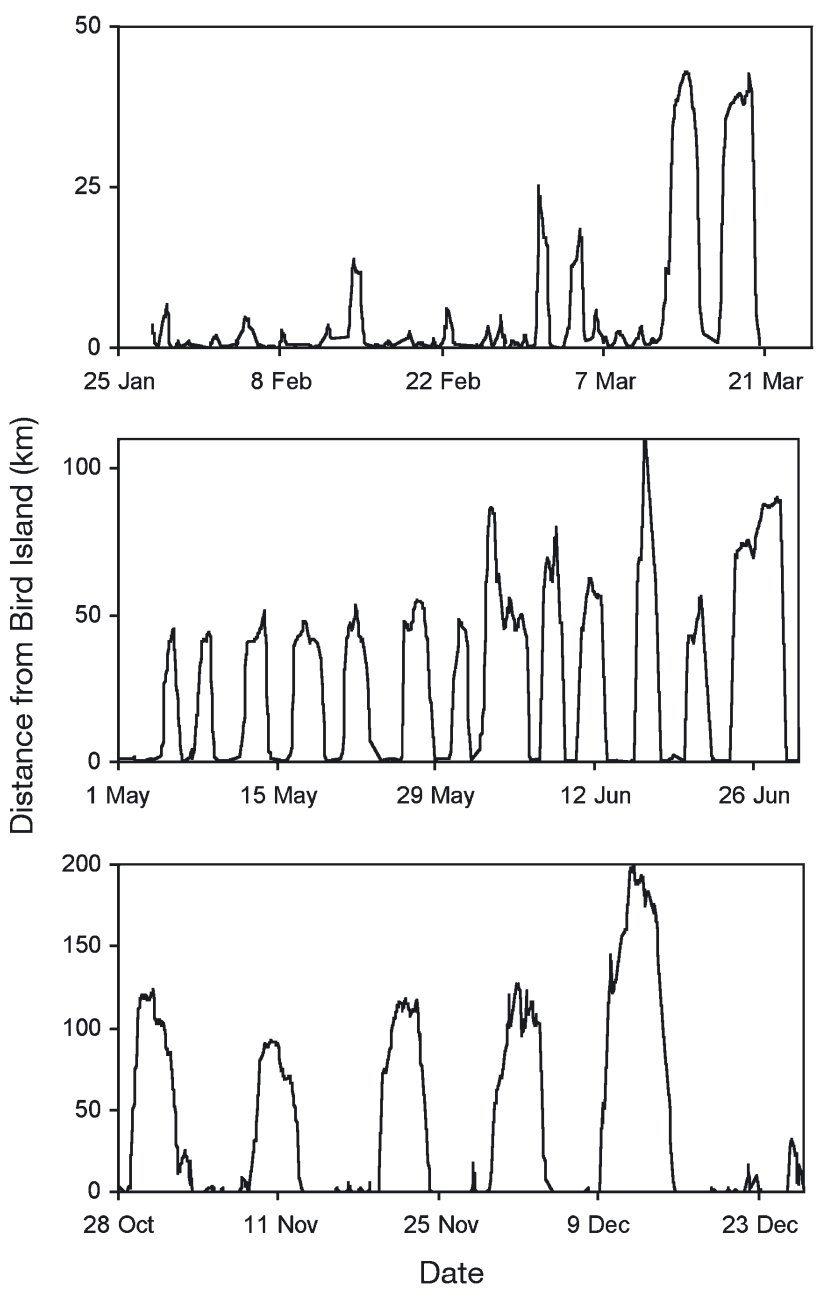

Fig. 6. Arctocephalus australis. Examples of movement/ foraging-trip patterns of females, presented as distance from breeding site at different stages of the breeding cycle. Maximum distance from breeding site and trip duration increased throughout year. Note different scaling of axes in each plot
In late April, 2 post-moult fur seals were tagged. Trips by these 2 seals during May were similar in duration and distance to those of the 5 seals tracked in March, with foraging concentrated around Beaver Island (Fig. 5d). In early June, the seals simultaneously switched foraging sites, concentrating on 2 areas approximately 60 and $100 \mathrm{~km}$ east-southeast of Bird Island (Fig. 5e). After the switch in foraging locations, trip duration $(t=3.2, \mathrm{p}<0.01)$, duration of visits to the breeding site $(t=2.3, \mathrm{p}<0.05)$ and trip distance $(t=7.7, \mathrm{p}<0.001)$ were all significantly higher.

Trip distances, trip durations and lengths of visits increased throughout the season (Fig. 6). Data were pooled for all seals and regressed on day number (approximately equal to the age of the pups). All increased significantly throughout the year (trip distance $=3.4+0.22$ (date) $;$ df $=263,1 ; \mathrm{R}^{2}=0.30 ;$ $\mathrm{p}<0.001 ;$ trip duration $=7.5+0.21$ (date) $; \mathrm{df}=263,1$; $\mathrm{R}^{2}=0.25 ; \mathrm{p}<0.001 ;$ visit duration $=1.9+0.08($ date $) ;$ df $\left.=253,1 ; R^{2}=0.10 ; p<0.001\right)$.

\section{Patch locations}

Periods of slow horizontal travel were generally restricted to discrete patches during the mid part of each foraging-trip (Fig. 5a,c). Trips comprised rapid swimming away from the colony, followed by 1 or more periods of relatively slow swimming and then a period of rapid swimming back to the colony. The slow swimming sections are assumed to represent periods when seals were in foraging patches.

There was no clear water-depth preference, with seals apparently foraging in water ranging from $<50$ to $>600 \mathrm{~m}$ deep. Throughout the late summer and autumn, tracked seals concentrated their foraging effort close to fur seal breeding-sites. During the late summer and autumn, 93.5\% of slow-swimming position-fixes were within $25 \mathrm{~km}$ of a fur seal breeding site, whereas during winter and spring, only $11.5 \%$ of foraging position-fixes were within $25 \mathrm{~km}$ (Fig. 7).

Females usually left the colony in the evening and returned during the early morning; $90 \%$ of trips started 
between 16:00 and 24:00 $\mathrm{h}$ and $87 \%$ of trips ended between 00:00 and 09:00 h local time. Thus, at least during the period January to March when trips were generally short, female fur seals were foraging exclusively at night.

\section{DISCUSSION}

Our results represent the first successful attempts to track South American fur seals at sea. The telemetry techniques used, after suitable smoothing, allowed us to examine fur seal movements at an unprecedented resolution.

\section{Smoothing algorithm}

The smoothing algorithm developed for the fur seal satellite-track data improved the apparent resolution of the tracking data. By applying an appropriately weighted smoothing function, we dramatically reduced the noise in the system. By incorporating basic information on the biology of the species (i.e. haulout fidelity) and the behaviour of the tracking system (i.e. the probability of receiving signals in a particular behaviour state) we were able to resolve the track data to identify short-duration, short-distance trips which would otherwise have been missed.

Such short-duration short-distance trips would have been swamped by residual location error in data passed through a swim-speed filter. In addition, the smoothed data appear to show behavioural information within trips that had previously been masked by noise. The improvement in the apparent resolution was sufficient to differentiate between short periods of directed rapid swimming and periods of localised slow swimming. We interpret these as travelling and foraging behaviour respectively. We have no dive-behaviour data to verify this interpretation, but if correct it may allow us to accurately identify foraging sites within trips.

\section{Validation of smoothing algorithm}

The TDR data allowed us to independently corroborate a sample of the short-duration foraging trips that were identified after the smoothing operation. The start and end times of trips in TDR data were estimated from the wet/dry sensor, i.e. the times when the seals entered or left the water, and were therefore reliable and accurate. The equivalent departure and return times from the smoothed tracks were estimated by eye and were probably less accurate. Despite this discrep-

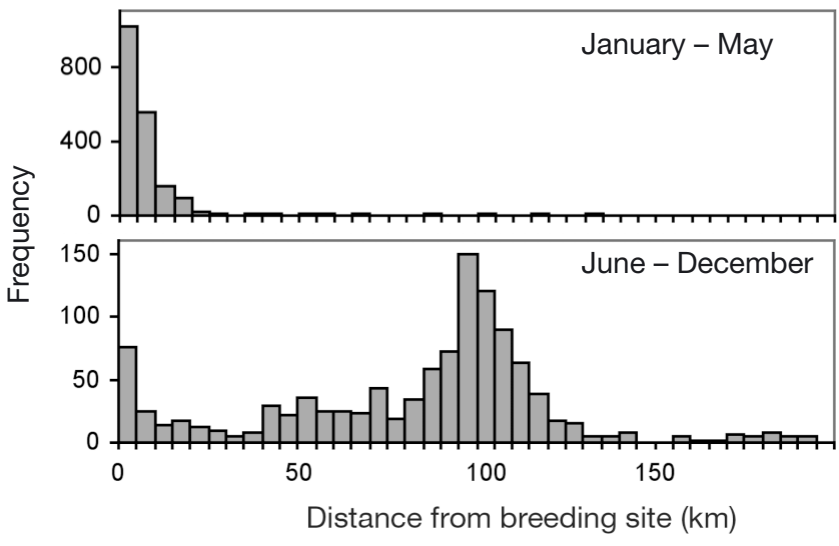

Fig. 7. Arctocephalus australis. Frequency distribution of slow-swimming locations against distance from breeding sites. Between January and May, $>93 \%$ of locations were within $25 \mathrm{~km}$ of a breeding site. Between June and September, $<11 \%$ were within $25 \mathrm{~km}$

ancy, the times estimated from smoothed track-data agreed well with those from TDR data.

The smoothing algorithm therefore provides an improved means of extracting information on shortduration local movements from apparently lowresolution satellite-tracking data.

The assumption that signal receptions were random events is not strictly correct. Seal surfacing behaviour would be random with respect to satellite passes but, within a pass, successive uplinks are clearly related. In addition, the pattern of overflights by the NOAA (National Oceanic and Atmospheric Administration) satellites is not uniform outside the dead period (16:00 to 20:00 h). However, the threshold of $3 \mathrm{~h}$ without an uplink, used to detect a probable haulout event, was conservative. For most of the day, the uplink reception rate was over 3 uplinks $\mathrm{h}^{-1}$, so the likelihood of no uplinks in $3 \mathrm{~h}$ would have fallen to less than 0.0003. The close agreement between trip durations estimated from the smoothed data and the swimming-behaviour data shows that the method is effective.

The value of the bandwidth parameter for the timeweighted smoothing algorithm was determined by simulation. The temporal pattern of locations and the LQ values used in the simulations were based on the observed patterns received from one of the study seals during a period when it was performing daily foraging trips. Accordingly, the simulated cyclical tracks were given a periodicity of approximately 1 cycle $\mathrm{d}^{-1}$. Thus, the value chosen for the smoothing bandwidth parameter should be appropriate to the behaviour of fur seals during the early breeding season. If trips were much shorter, there could be potential problems due to aliasing effects. For example, in extreme cases, loca- 
tions from several successive trips could be given significant weighting and would influence the apparent location of the smoothed points. As a result, the apparent movements would be highly damped to the extent that compete trips might not appear in the smoothed records. However, this situation did not arise in the fur seal study. Trip frequency decreased throughout the year and potential aliasing problems would therefore have decreased also.

A time-weighted running average applied to intermittent location data should converge on the true location for a stationary transmitter. When applied to a moving transmitter the smoothed track can only provide an approximation of the true path. When, as in this case, the frequency of locations is high relative to the travel speed and the variance of location estimates is large relative to the distances moved between points, the use of a weighted running average can clearly improve the path estimates.

The success of the algorithm was due, in part, to the behaviour of the study species at this location. However, similar smoothing algorithms using appropriate time and location-quality weighting factors will be applicable to other satellite-tracking studies or any studies where location estimates can be assigned an appropriate error distribution. If, as in this case, biological knowledge can be used to put feasible bounds on the behaviour of the tracked animals (e.g. by adding in known locations with appropriate weightings) the apparent resolution of a tracking system may be enhanced.

\section{Seasonal distribution}

There were distinct seasonal differences in foraging distribution. Foraging activity was very tightly clustered around Bird Island in the early part of the breeding season. This activity comprised almost daily, short-duration, nocturnal foraging trips. Nocturnal foraging has been documented for several fur seal species (e.g. Harcourt et al. 1995, Georges et al. 2000b, Lea et al. 2002) during long multi-day foraging trips, and has been described as the typical pattern for pelagic-foraging fur seals (Lea et al. 2002). Similar short nocturnal-foraging trips, classified as overnightforaging trips (OFT), have been recorded in sympatric, lactating female Arctocephalus gazella and A. tropicalis, foraging around Macquarie Island (Goldsworthy 1999) and A. forsteri in New Zealand (Harcourt et al. 2001), where OFTs accounted for up to $41 \%$ of trips in some seasons but were rare or absent in others. In those studies, OFTs were interspersed with longer-duration trips and were assumed to represent switching between more usual remote feeding sites and much nearer food sources. In our study, almost all foraging activity during the early lactation period was in the form of OFTs. Trip duration increased during mid-lactation, but the majority of efforts was still concentrated close to fur seal breeding-sites. This concentration of effort suggests that predation pressure on local prey populations may be high. Unfortunately we do not have information on local prey availability. However, it appears that during the summer and autumn the availability of prey close to the breeding colonies remains high enough to make local foraging the preferred option. The observation that the single sub-adult male also restricted foraging to this small area suggests that food availability was probably high.

In autumn, both distance and time away from the breeding site increased. The dispersal of foraging effort later in the season may indicate a relative increase in prey density further from the Island. Alternatively, it may be a response to a change in the metabolic requirements of the pups and females. In early summer, the pups are small and may benefit from frequent, relatively small meals. Although pups of similar-sized fur seal species are known to withstand much longer intersuckling intervals, e.g. up to $10 \mathrm{~d}$ early in lactation in Arctocephalus tropicalis (Georges \& Guinet 2000), pups of females that performed short, regular foraging trips grew faster and were heavier at weaning than other pups (Lunn et al. 1993, Guinet \& Georges 2000). Later in the season, when pups are capable of withstanding longer fasts and metabolic demands of pregnancy and lactation are higher, it may be more efficient for females to stay at sea longer and forage in more distant patches.

From a management perspective, the reasons for the seasonal patterns are not particularly important, but their implications may be. The predation pressure induced by so many fur seals feeding close to the islands means that it is possible that local prey stocks become depleted and seals may be forced to move out to find new sources. The reliance on such a small area for foraging early in the season may indicate that disturbance to that area at that time could have serious implications for pup survival.

The fact that females apparently ranged up to $195 \mathrm{~km}$ from the colony during the later part of the season, and showed no clear preferred direction, suggests that any disturbance within $200 \mathrm{~km}$ of the island could adversely affect their foraging success. Whereas other marine predators may be able to search for and exploit new foraging areas, the fact that South American fur seals are constrained to return to feed pups throughout the year means that they have limited ability to move in response to disturbance. 


\section{Potential interaction with offshore oil activities}

Of the female fur seals tagged at Bird Island, 5 foraged in the proposed oil exploration area southwest of the Falklands Islands. During October to December 1999 and March 2000, around $20 \%$ of their time at sea was spent within the licensed area. The relative importance of this area is difficult to assess because of the small sample size during these periods, but the zone is clearly within the normal foraging range of the Bird Island fur seals and may be important for breeding females late in the season.

The smoothing algorithm improved the spatial resolution sufficiently to allow us to identify areas of apparent foraging effort within individual trips. The study seals did not show any clear preference for particular water depths and there were no obvious year-round foraging hotspots. There was, however, a clear concentration of foraging in inshore waters adjacent to fur seal breeding-colonies during the first half of lactation, and the start and end times of foraging trips during the same period suggest that foraging was restricted to night time.

With the important caveat that we have only 1 year's data, our results suggest that there was little likelihood of direct interactions with offshore activities during the first half of the lactation period. The nocturnal activity patterns suggests that, for lactating fur seals, disruption to foraging could be minimised by restricting potentially disturbing activities to daylight hours. Counterintuitively, from the South American fur seal's perspective it may be better to carry out potentially disturbing offshore activities during the early puprearing period while foraging range is restricted both geographically and temporally.

Acknowledgements. The work was funded by the Falkland Islands and supported by the UK's Natural Environment Research Council through the Sea Mammal Research Unit. INMARSAT provided invaluable satellite communications in the field. We would like to thank T. Eggling for his help with the management of the project and with obtaining licences and permission to work on Falkland Island nature reserves. Special thanks are due to M. Riddy for help in the field, to staff at Falklands Conservation for their help and advice throughout the project, and to $\mathrm{M}$. and J. Clark for taking us out to Bird Island in all sorts of weather.

\section{LITERATURE CITED}

Agardy T (2000) Effects of fisheries on marine ecosystems: a conservationist's perspective. ICES J Mar Sci 57:761-765 Argos (1989) Guide to the Argos system. Argos CLS, Toulouse Austin D, McMillan JI, Bowen WD (2003) A three-stage algorithm for filtering erroneous Argos satellite locations. Mar Mamm Sci 19:371-383

Baker JR, Fedak MA, Anderson SS, Arnbom T, Baker R (1990)
Use of a tiletamine-zolazepam mixture to immobilise wild grey seals and southern elephant seals. Vet Rec 126:75-77

Britten MW, Kennedy PL, Ambrose S (1999) Performance and accuracy evaluation of small satellite transmitters. J Wildl Manag 63:1349-1358

Campagna C, Werner R, Karesh W, Marin MR, Koontz F, Cook R, Koontz C (2001) Movements and location at sea of South American sea lions (Otaria flavescens). J Zool 255: 205-220

Catard A, Weimerskirch H, Cherel Y (2000) Exploitation of distant Antarctic waters and close shelf-break waters by white-chinned petrels rearing chicks. Mar Ecol Prog Ser 194:249-261

Fedak MA, Anderson SS, Curry MG (1983) Attachment of a radio tag to the fur of seals. J Zool 200:298-300

Georges JY, Guinet C (2000) Maternal care in the subantarctic fur seals on Amsterdam Island. Ecology 81:295-308

Georges JY, Bonadonna F, Guinet C (2000a) Foraging habitat and diving activity of lactating subantarctic fur seals in relation to sea-surface temperatures at Amsterdam Island. Mar Ecol Prog Ser 196:291-304

Georges JY, Tremblay Y, Guinet C (2000b) Seasonal diving behaviour in lactating subantarctic fur seals on Amsterdam Island. Polar Biol 23:59-69

GESAMP (1998) Report of the 28th session of the Group of Experts on the Scientific Aspects of Marine Environmental Protection, Vol 66. United Nations, Geneva

Goldsworthy SD (1999) Maternal attendance behaviour of sympatrically breeding Antarctic and subantarctic fur seals, Arctocephalus spp., at Macquarie Island. Polar Biol 21:316-325

Guinet C, Georges JY (2000) Growth in pups of the subantarctic fur seal (Arctocephalus tropicalis) on Amsterdam Island. J Zool 251:289-296

Harcourt RG, Schulman AM, Davis LS, Trillmich F (1995) Summer foraging by lactating female New-Zealand fur seals (Arctocephalus forsteri) off Otago Peninsula, New Zealand. Can J Zool 73:678-690

Harcourt RG, Bradshaw CJA, Davis LS (2001) Summer foraging behaviour of a generalist predator, the New Zealand fur seal (Arctocephalus forsteri). Wildl Res 28:599-606

Hays GC, Akesson S, Godley BJ, Luschi P, Santidrian P (2001) The implications of location accuracy for the interpretation of satellite-tracking data. Anim Behav 61:1035-1040

Hull CL, Hindell MA, Michael K (1997) Foraging zones of Royal penguins during the breeding season, and their association with oceanographic features. Mar Ecol Prog Ser 153:217-228

Jouventin P, Weimerskirch H (1990) Satellite tracking of wandering albatrosses. Nature 343:746-748

Keating KA (1994) An alternative index of satellite telemetry location error. J Wildl Manag 58:414-421

Keating KA (1995) Mitigating elevation-induced errors in satellite telemetry locations. J Wildl Manag 59:801-808

Lea MA, Hindell M, Guinet C, Goldsworthy S (2002) Variability in the diving activity of Antarctic fur seals, Arctocephalus gazella, at Îles Kerguelen. Polar Biol 25:269-279

Lunn NJ, Boyd IL, Barton T, Croxall JP (1993) Factors affecting the growth-rate and mass at weaning of Antarctic fur seals at Bird Island, South Georgia. J Mammal 74:908-919

McConnell BJ, Fedak MA (1996) Movements of southern elephant seals. Can J Zool 74:1485-1496

McConnell BJ, Chambers C, Fedak MA (1992a) Foraging ecology of southern elephant seals in relation to the bathymetry and productivity of the Southern Ocean. Antarct Sci 4:393-398

McConnell BJ, Chambers C, Nicholas KS, Fedak MA (1992b) 
Satellite tracking of grey seals (Halichoerus grypus). J Zool 226:271-282

McConnell BJ, Fedak MA, Lovell P, Hammond PS (1999) Movements and foraging areas of grey seals in the North Sea. J Appl Ecol 36:573-590

Merrick RL, Loughlin TR, Antonelis GA, Hill R (1994) Use of satellite-linked telemetry to study steller sea lion and northern fur-seal foraging. Polar Res 13:105-114

Northridge S (2001) Fishing industry: effects of. In: Perrin WF,

Editorial responsibility: Otto Kinne (Editor),

Oldendorf/Luhe, Germany
Wursig B, Thewissen JGM (eds) Encyclopedia of marine mammals. Academic Press, San Diego

Vincent C, McConnell BJ, Ridoux V, Fedak MA (2002) Assessment of Argos location accuracy from satellite tags deployed on captive gray seals. Mar Mamm Sci 18: 156-166

Walton LR, Cluff HD, Paquet PC, Ramsay MA (2001) Performance of 2 models of satellite collars for wolves. Wildl Soc Bull 29:180-186

Submitted: October 18, 2002; Accepted: May 8, 2003

Proofs received from author(s): September 8, 2003 